\title{
Insulin action and non-esterified fatty acids
}

\author{
BY E. FERRANNINI ${ }^{1}$, S. CAMASTRA ${ }^{1}$, S. W. COPPACK ${ }^{2}$, D. FLISER ${ }^{3}$, A. GOLAY $^{4}$ AND \\ A. MITRAKOU ${ }^{5}$, ON BEHALF OF THE EUROPEAN GROUP FOR THE STUDY OF \\ INSULIN RESISTANCE (EGIR)* \\ ${ }^{\prime}$ CNR Institute of Clinical Physiology, Via Savi 8, 56126 Pisa, Italy \\ ${ }^{2}$ Centre for Diabetes and Cardiovascular Risk, University College London Medical School, \\ Whittington Hospital, London N19 3UA \\ ${ }^{3}$ Department of Internal Medicine, Ruperto-Carola University, Heidelberg, Germany \\ ${ }^{4}$ Department of Medicine, Geneva University Hospital, Geneva, Switzerland \\ ${ }^{5}$ Second Department of Internal Medicine, Propaedeutic, Athens University, Athens, Greece
}

Non-esterified fatty acids (NEFA) are the primary energy fuel for most tissues under fasting conditions. Their release into the circulation results partly from the hydrolysis of triacylglycerol-rich lipids under the action of lipoprotein lipase (EC 3.1.1.34; LPL). The circulating NEFA pool is in dynamic equilibrium with an interstitial pool, into which NEFA are also released from tissue triacylglycerol depots under the influence of hormonesensitive lipase (EC 3.1.1.3; HSL). NEFA removal is dependent on tissue uptake for oxidation or re-esterification. Insulin is a potent regulator of circulating NEFA concentrations through a stimulatory effect on LPL and an inhibitory effect on HSL; by enhancing glucose uptake and glycolysis, insulin also provides $\alpha$-glycerophosphate, the substrate for NEFA re-esterification (Campbell et al. 1992). The net effect of systemic insulinization is a prompt, marked decline in circulating NEFA concentrations, which marks the switch of energy production from dominant fat oxidation to prevalent carbohydrate utilization. This action of insulin is impaired in patients with non-insulin-dependent diabetes (NIDDM), in whom day-long plasma NEFA levels are elevated despite normal plasma insulin concentrations (Golay et al. 1986a). Raised NEFA concentrations have also been reported in non-diabetic obese subjects (Golay et al. 1986b; Frayn et al. 1996).

According to the concept of substrate competition (Randle et al. 1963), the ability of insulin to restrain lipolysis is part of its action on glucose metabolism. By reducing fatty substrate availability, insulin promotes glucose transfer into target tissues by a combination of push (activation of membrane transport) and pull mechanisms (stimulation of glycogen synthesis, anaerobic glycolysis, and pyruvate oxidation; Groop \& Ferrannini, 1993). Thus, insulin resistance in the lipolytic pathway is associated with insulin resistance of glucose metabolism as well as abnormal lipid metabolism (Reaven et al. 1988; Groop et al. 1991; McGarry, 1992).

The relative influence of obesity and insulin resistance on plasma NEFA concentrations has not been established, nor has the impact of physiological factors such as sex and age been considered. In the present work, we have assessed the relationship between NEFA and insulin action by retrospective analysis of the database of the European Group for the Study of Insulin Resistance (EGIR; Ferrannini et al. 1996). This database, collected at twenty-one European centres, includes data from 1146 healthy Caucasian men and women, ranging in age from 18 to 85 years, in whom insulin action was determined by the euglycaemic insulin clamp technique. This population sample is the largest so far in which insulin action has been measured directly.

\footnotetext{
* For details, see Appendix.
} 


\section{MATERIALS AND METHODS}

\section{Subjects}

Twenty-one clinical research centres in Europe (three in Finland, one in Sweden, two in UK, one in Denmark, four in Germany, one in Switzerland, seven in Italy, one in Yugoslavia and one in Greece) each contributed between twenty-one and 122 subjects. These centres agreed to provide their available clamp studies (whatever the original purpose of these studies) on the condition that the study subjects met the following criteria: (a) no clinical or laboratory evidence of cardiac, renal, liver, or endocrine disease, (b) a fasting plasma glucose concentration $<6.7 \mathrm{mmol} / \mathrm{l}$ and normal glucose tolerance by World Health Organization (WHO) criteria (WHO Expert Committee on Diabetes Mellitus, 1980 ), (c) normal blood pressure, (d) no recent change ( $\geq 10 \%$ ) in body weight, and (e) no current medication. Of the 1146 subjects in the present series ( 766 men and 380 women), 425 were recruited in northern Europe (Sweden, Finland and UK), 289 in central Europe (Denmark, Germany and Switzerland), and 432 in southern Europe (Italy, Serbia and Greece). At each centre, the protocol was reviewed and approved by the local Ethics Committee, and informed consent was obtained from all subjects before their participation.

\section{Protocol}

The minimum of information required for each subject was: age, anthropometric variables, fasting and steady-state (last $40 \mathrm{~min}$ of a $2 \mathrm{~h}$ clamp) plasma glucose and insulin measurements. Height was measured to the nearest $0.01 \mathrm{~m}$, weight to the nearest kilogram. BMI was calculated as the weight $(\mathrm{kg})$ divided by the square of height $(\mathrm{m})$. The waist: hip circumference ratio (WHR) was determined (in a subset of 372 men and 157 women) by measuring the waist circumference at the narrowest part of the torso, and the hip circumference in a horizontal plane at the level of the maximal extension of the buttocks.

Insulin action was measured in all subjects by the euglycaemic insulin clamp technique (DeFronzo et al. 1979) using an insulin infusion rate of $1 \mathrm{mU} / \mathrm{min}$ per $\mathrm{kg}(6 \mathrm{pmol} / \mathrm{min}$ per $\mathrm{kg}$ ). Briefly, polyethylene cannulas were inserted into an antecubital vein (for the infusion of glucose and insulin) and retrogradely into a wrist vein heated at $60^{\circ}$ in a hot box or a heating pad (for intermittent blood sampling of arterialized venous blood). At time zero, a primed constant infusion of regular insulin was begun, and continued for $120 \mathrm{~min}$. At $4 \mathrm{~min}$ into the insulin infusion, an exogenous glucose infusion was started, and adjusted every 5$10 \mathrm{~min}$ in order to maintain plasma glucose within approximately $10 \%$ of its baseline value. Blood samples were obtained at timed intervals in the fasting state and during the clamp, for the measurement of plasma glucose, insulin and NEFA levels. The latter were measured in a subset of 347 men and 160 women. In this subgroup, WHR was available for 164 men and fifty-nine women.

\section{Analytical procedures}

Plasma glucose was measured by the glucose oxidase ( $E C$ 1.1.3.4) method. Plasma insulin concentrations were measured by radioimmunoassay. Plasma NEFA were assayed spectrophotometrically.

\section{Data analysis}

Insulin action was expressed as the whole-body glucose disposal rate (M) during steadystate euglycaemic hyperinsulinaemia. With the insulin dose used in the current study, hepatic glucose output has been previously shown to be fully suppressed in old as well as 
young subjects (DeFronzo, 1979; Robert et al. 1982; Fink et al. 1986). Thus, M was calculated from the exogenous glucose infusion rate during the last $40 \mathrm{~min}$ of the $2 \mathrm{~h}$ clamp, after correction for changes in glucose concentration in a total distribution volume of $250 \mathrm{ml} / \mathrm{kg}$ (Ferrannini et al. 1985). M was normalized on a per $\mathrm{kg}$ fat-free mass basis $\left(\mathrm{M}_{\mathrm{FFM}}\right)$, as calculated by Hume's (1966) formula. Fat mass was obtained as the difference between body weight and fat-free mass. Fasting NEFA level was the average of two baseline samples, and steady-state NEFA concentration was the average of three samples obtained during the final 60 min of insulin infusion.

Plasma insulin and NEFA values were log-transformed to normalize their distribution. Data are given as means with their standard errors. A dummy variable was introduced to account for between-centre differences, and was included in all regression models. The $95 \% \mathrm{CI}$ were calculated for regression coefficients.

\section{RESULTS}

The clinical and metabolic variables of the study group are given in Tables 1 and 2 . Both fasting and steady-state plasma NEFA levels were significantly higher in women than in men $(P<0.0001$ for both). In univariate association, higher fasting NEFA levels were significantly related to increasing age and to higher BMI (or fat mass), but were not related to fasting plasma glucose or insulin concentrations. Higher fasting NEFA were also related to insulin insensitivity (Fig. 1); this relationship remained highly significant $(P<0 \cdot 0001)$ in a multiple-regression model adjusting for age, sex, and BMI (13\% of the variability of fasting NEFA concentrations being explained).

By defining obesity as a BMI $>25 \mathrm{~kg} / \mathrm{m}^{2}$, and insulin resistance as the lower $10 \%$ of values of the lean subgroup (Table 3 ), the 174 obese individuals and the 246 lean subjects who were insulin sensitive (i.e. had similar $\mathbf{M}_{\mathrm{FFM}}$ values) had comparable fasting NEFA concentrations. Likewise, fasting NEFA were similarly raised in obese and lean subjects with insulin resistance. Following euglycaemic insulin administration, circulating NEFA were suppressed by 84 (SE 15$) \%$ in the whole study group $(P<0.0001$; Table 2 ). Steadystate NEFA concentrations were inversely related to insulin sensitivity, the regression line being significantly $(P<0.0001)$ steeper than that between fasting NEFA and insulin sensitivity (Fig. 1). Thus, age-, sex-, and BMI-adjusted fasting NEFA are predicted to be $532 \mu \mathrm{mol} / \mathrm{l}$ (CI 481-559) in an insulin-sensitive subject (46-year-old male with a BMI of $26 \mathrm{~kg} / \mathrm{m}^{2}$ and an $\mathrm{M}_{\mathrm{FFM}}$ value of $50 \mu \mathrm{mol} / \mathrm{min}$ per $\mathrm{kg}$ ), and $588 \mu \mathrm{mol} / 1$ (CI 559-603) in his insulin-resistant counterpart $\left(\mathrm{M}_{\mathrm{FFM}} 25 \mu \mathrm{mol} / \mathrm{min}\right.$ per $\left.\mathrm{kg}\right)$, an $11 \%$ increase. The

Table 1. Characteristics of the study group which included subjects from twenty-one clinical research centres in Europe*

(Mean values and standard deviations)

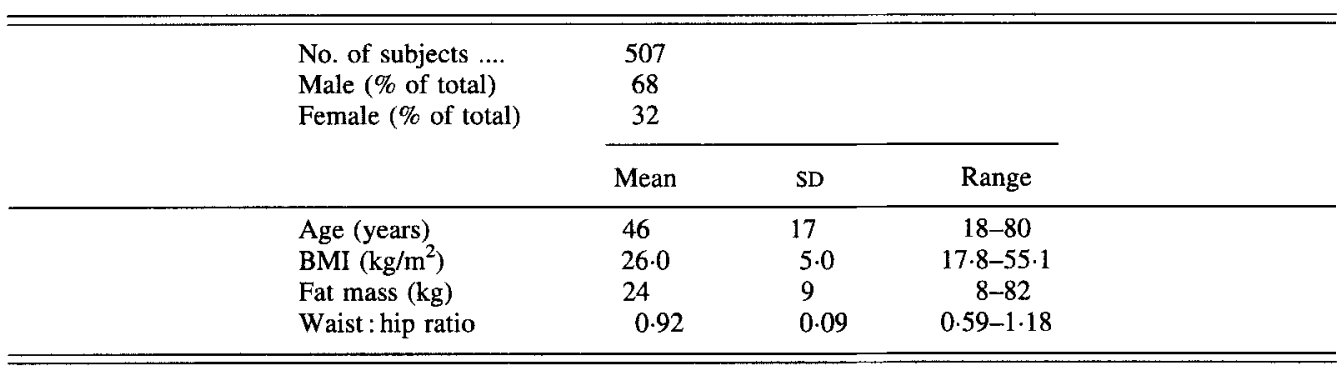

* For details, see p. 754. 
Table 2. Metabolic variables of the study group which included subjects from twenty-one clinical research centres in Europe*

(Mean values and standard deviations)

\begin{tabular}{lccc}
\hline \hline & Mean & SD & Range \\
\hline Fasting plasma glucose $(\mathrm{mmol} / \mathrm{l})$ & $5 \cdot 1$ & 0.5 & $3 \cdot 7-6 \cdot 5$ \\
Fasting plasma insulin $(\mathrm{pmol} / \mathrm{l})$ & 62 & 37 & $10-343$ \\
Steady-state plasma glucose $(\mathrm{mmol} / \mathrm{l})$ & $5 \cdot 1$ & 0.5 & $3 \cdot 6-7 \cdot 0$ \\
Steady-state plasma insulin $(\mathrm{pmol} / \mathrm{l})$ & 501 & 141 & $213-1198$ \\
$\mathrm{M}_{\mathrm{FFM}}(\mu \mathrm{mol} / \mathrm{min}$ per $\mathrm{kg})$ & $49 \cdot 7$ & $18 \cdot 0$ & $5 \cdot 2-118 \cdot 3$ \\
Fasting NEFA $(\mu \mathrm{mol} / \mathrm{l})$ & 587 & 218 & $106-1652$ \\
Steady-state NEFA $(\mu \mathrm{mol} / \mathrm{l})$ & 93 & 91 & $15-595$ \\
\hline \hline
\end{tabular}

$\mathrm{M}_{\mathrm{FFM}}$, whole-body glucose disposal normalized on a per $\mathrm{kg}$ fat-free mass (FFM) basis; NEFA, non-esterified fatty acids. * For details, see p. 754.

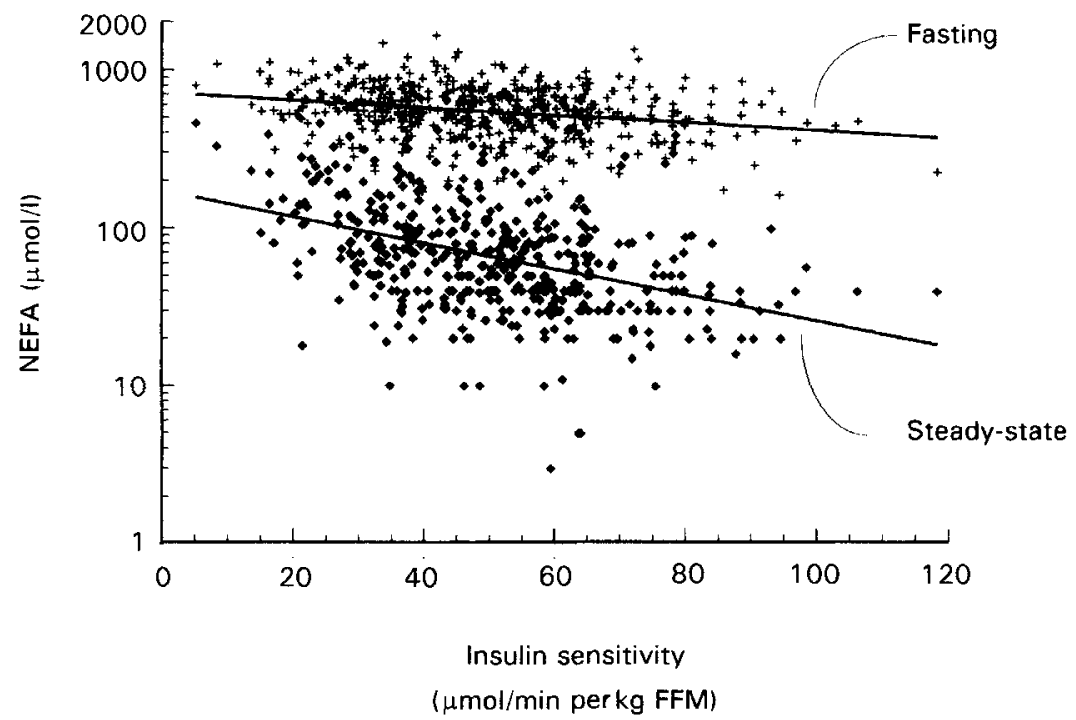

Fig. 1. Relationship between fasting and post-insulin plasma non-esterified acid (NEFA) concentrations in 507 healthy subjects from twenty-one clinical research centres in Europe (for details, see p. 754). Values are plotted on a log scale. FFM, fat-free mass

corresponding predictions for steady-state NEFA levels are $67 \mu \mathrm{mol} / \mathrm{l}$ (CI 55-86) and 105 $\mu \mathrm{mol} / 1$ (CI 95-119) respectively, a 57\% increase. In univariate analysis, insulin-induced suppression of fasting NEFA levels was positively related to age, female gender and insulin sensitivity (Fig. 2), and negatively related to BMI. By multiple regression, better suppression of NEFA continued to be reciprocally related to both BMI and insulin resistance, independently of one another.

When insulin sensitivity $\left(\mathrm{M}_{\mathrm{FFM}}\right)$ was set as the dependent variable in a multipleregression model with age, sex, BMI, and percentage suppression of NEFA levels as the independent variables, $16 \%$ of the inter-individual variability of $\mathrm{M}_{\mathrm{FFM}}$ was explained. Using the regression coefficients of this model together with the ranges of $M_{F F M}, B M I$ and NEFA suppression observed in the whole study group, the quantitative contribution of sex, BMI, and NEFA suppression to insulin sensitivity could be estimated (Fig. 3). It can be seen that the maximal independent contribution of NEFA inhibition to insulin-mediated 
Table 3. Characteristics of lean and obese subgroups of the study group which included subjects from twenty-one clinical research centres in Europe $\dagger$

(Mean values with their standard errors)

\begin{tabular}{|c|c|c|c|c|c|c|c|c|c|c|c|}
\hline \multirow{3}{*}{$\begin{array}{l}\text { Subgroup } \ldots \\
\text { Insulin sensitivity (I) } \ldots \\
n \ldots\end{array}$} & \multicolumn{4}{|c|}{ Lean } & \multicolumn{4}{|c|}{ Obese } & \multicolumn{3}{|c|}{$\begin{array}{c}\text { Statistical } \\
\text { significance } \\
\text { of effect of } \ddagger \text { : }\end{array}$} \\
\hline & \multicolumn{2}{|c|}{$\begin{array}{c}\text { Sensitive } \\
246\end{array}$} & \multicolumn{2}{|c|}{$\begin{array}{c}\text { Resistant } \\
21\end{array}$} & \multicolumn{2}{|c|}{$\begin{array}{c}\text { Sensitive } \\
174\end{array}$} & \multicolumn{2}{|c|}{$\begin{array}{c}\text { Resistant } \\
\quad 66\end{array}$} & \multirow[b]{2}{*}{ I } & \multirow{2}{*}{$\begin{array}{l}\text { Obesity } \\
\text { (O) }\end{array}$} & \multirow[b]{2}{*}{$\mathrm{I} \times \mathrm{O}$} \\
\hline & Mean & SE & Mean & SE & Mean & SE & Mean & SE & & & \\
\hline BMI $\left(\mathrm{kg} / \mathrm{m}^{2}\right)$ & $22 \cdot 6$ & 0.1 & $23 \cdot 2$ & 0.4 & 28.7 & 0.3 & 31.9 & 0.8 & ** & * & * \\
\hline Fat mass $(\mathrm{kg})$ & 18 & 0.2 & 19 & 0.8 & 29 & 0.6 & 36 & 1.5 & $* *$ & * & $*$ \\
\hline Fasting NEFA $(\mu \mathrm{mol} / \mathrm{l})$ & 563 & 13 & 707 & 55 & 578 & 17 & 663 & 25 & $* *$ & & \\
\hline FPI $(\mathrm{pmol} / \mathrm{l})$ & 47 & 1 & 67 & 6 & 65 & 2 & 110 & 8 & $* *$ & * & * \\
\hline SSPI (pmol/1) & 451 & 7 & 495 & 28 & 538 & 11 & 594 & 20 & ** & * & \\
\hline $\mathbf{M}_{\mathrm{FFM}}(\mu \mathrm{mol} / \mathrm{min}$ per $\mathrm{kg})$ & $56 \cdot 8$ & 0.9 & $25 \cdot 8$ & 0.9 & $52 \cdot 0$ & $1 \cdot 2$ & $24 \cdot 7$ & 0.7 & $* *$ & & \\
\hline
\end{tabular}

NEFA, non-esterified fatty acids; FPI, fasting plasma insulin concentration; SSPI, steady-state plasma insulin level; $\mathrm{M}_{\mathrm{FFM}}$, whole-body glucose disposal normalized on a per $\mathrm{kg}$ fat-free mass (FFM) basis.

$* P<0.05$, ** $P<0.01$.

$\dagger$ For details, see p. 754 .

$\ddagger$ Two-way ANOVA.

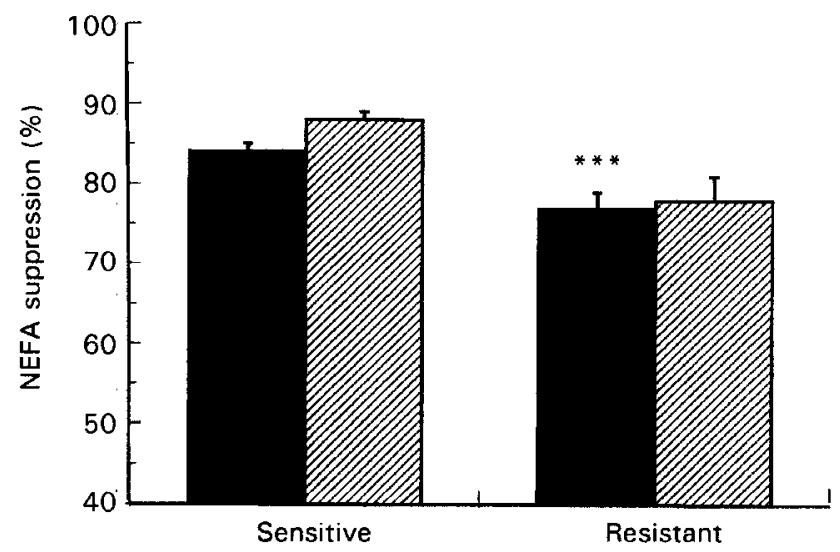

Fig. 2. Percentage suppression of circulating non-esterified fatty acid (NEFA) levels during a euglycaemic insulin clamp in insulin-sensitive and insulin-resistant men $(\boldsymbol{E})$ and women $(\mathbb{Z})$. Values are means with 1 SEM represented by vertical bars. Mean values for insulin-resistant men and women were significantly different from those for insulin-sensitive men and women: $* * * P<0.001$.

glucose uptake was approximately half that of BMI. The WHR was not significantly associated with any NEFA measure, in men or women.

\section{DISCUSSION}

Our study group only included individuals with normal glucose tolerance and arterial blood pressure. Nonetheless, biological variables characteristically related to age, such as the BMI, percentage fat mass, WHR, blood pressure, and plasma glucose and LDL-cholesterol levels, did show the expected rise with age, as previously reported (Ferrannini et al. 1996). 


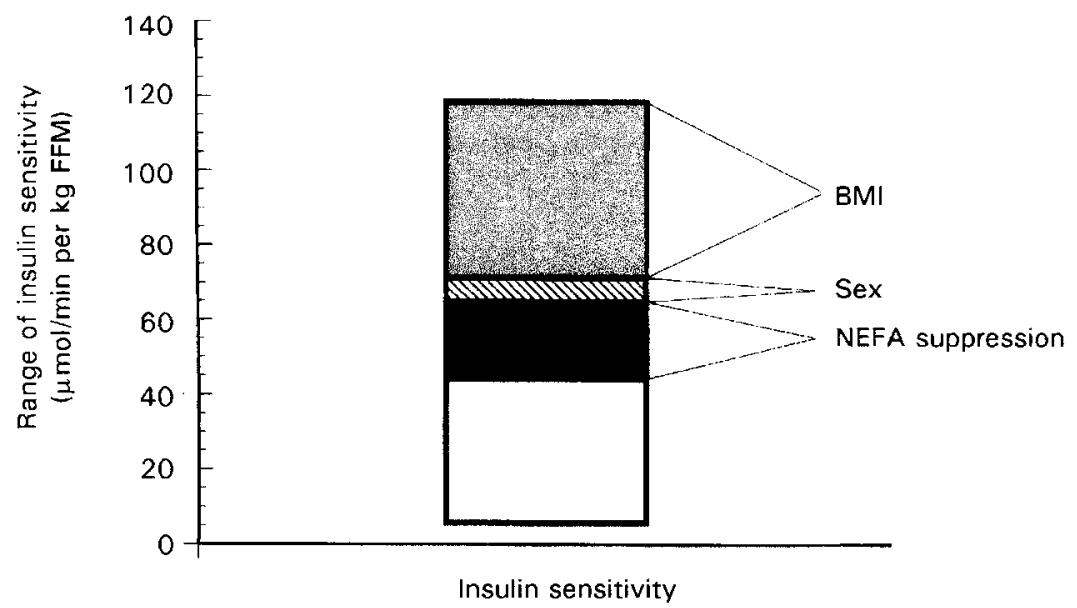

Fig. 3. Maximal contribution of gender, BMI, and percentage suppression of circulating non-esterified fatty acid (NEFA) levels to the observed range of insulin sensitivity (as the whole-body glucose disposal normalized on a per $\mathrm{kg}$ fat-free mass (FFM) basis) in 507 non-diabetic subjects from twenty-one clinical research centres in Europe (for details, see p. 754). Data were calculated from a multiple-regression model also adjusting for age and centre.

This confirms that our cohort, although not a random sample of the general population, still resembled a general population.

The first result of the present analysis is that fasting NEFA concentrations are raised in the presence of insulin resistance of glucose metabolism rather than in association with obesity per se. Thus, in obese subjects with preserved insulin sensitivity, fasting NEFA were similar to those of lean insulin-sensitive subjects (Table 3). This finding implies that, as long as glucose metabolism is normally sensitive to insulin, NEFA concentrations are normal in the fasting state regardless of fat mass.

It could be argued that, in obesity, normal absolute values of fasting NEFA are abnormal when viewed in the context of the raised fasting plasma insulin concentrations (Table 3; Coppack et al. 1994). However, in the obese, the total lipolytic flux must be increased simply because fat mass is expanded (Table 3 ). In fact, when NEFA levels are normalized by the fat mass, thereby yielding a rough index of intrinsic lipolytic activity, corrected NEFA values were $35 \%$ lower in obese than in lean individuals. The probable explanation for this phenomenon is that, in the lean individual, insulin resistance involves both glucose metabolism and lipolysis, and the compensatory hyperinsulinaemia is insufficient to normalize NEFA levels. In contrast, in the obese, insulin secretion is greatly enhanced, and the resulting hyperinsulinaemia is more than sufficient to restrain fasting NEFA release in the face of an enlarged fat mass and insulin resistance. An important corollary is that the obese non-diabetic subject compensates for any insulin resistance of glucose metabolism through the hyperinsulinaemia; the latter change, however, is maladaptive for lipolysis, resulting in reduced mobilization of triacylglycerol stores.

With acute insulin administration, on the other hand, the ability of the hormone to lower circulating NEFA was reduced as a function of both sensitivity of glucose metabolism and obesity per se. The simplest explanation of this finding is that, while in the fasting state the hyperinsulinaemia associated with obesity is capable of overcoming insulin resistance, the clamp conditions greatly reduce this compensation by essentially equalizing steady-state plasma insulin concentrations in obese and lean subjects (Table 2). Under non-clamp conditions, the endogenous insulin response in the obese individual is augmented in approximate proportion to the fasting hypersecretion (Polonsky et al. 1988); 
thus, obese subjects may control lipolysis throughout the day by virtue of enhanced $\beta$-cell function. When the ability of the $\beta$-cell to compensate for the insulin resistance of glucose metabolism is impaired, as in the case of diabetes, circulating NEFA are elevated throughout the day (Golay et al. 1986a).

Several studies have shown that body fat distribution plays a role in insulin sensitivity independent of total body adiposity (for example, see Coon et al. 1992; Kohrt et al. 1993). In the present data, WHR measures, available in a subgroup of 223 subjects rather evenly distributed between the lean and obese subgroup, were not significantly related to either fasting or post-insulin NEFA concentrations. This could be due to the fact that WHR is a poor proxy for intra-abdominal fat deposition, or to an insufficient number of observations (or a combination of the two factors). While it has been shown that lipolysis is higher in abdominal than peripheral fat depots (Arner, 1995), it should be considered that intraabdominal fat is only a small proportion of total fat mass. Thus, the contribution of abdominal fat to total lipolysis may be greatly diluted, and, therefore, only marginally related to NEFA concentrations in the peripheral circulation.

In multivariate analysis, insulin suppression of NEFA levels made a significant, independent contribution to insulin action on glucose uptake. This finding reflects the operations of Randle's cycle (Randle et al. 1963), i.e. inhibition of lipolysis leading to enhanced glucose uptake. In fact, the regression of our data indicated that an average $84 \%$ suppression of plasma NEFA is associated with an increase in glucose uptake of $17 \mu \mathrm{mol} /$ min per $\mathrm{kg}$. At the insulin levels achieved in the present clamp studies, approximately $40 \%$ of total glucose uptake is glucose oxidation (Bonadonna et al. 1990). At a circulating concentration of $0.6 \mathrm{mmol} \mathrm{NEFA} / \mathrm{l}$ (i.e. the average fasting level in the entire cohort), NEFA are oxidized at a rate of approximately $2 \mu \mathrm{mol} / \mathrm{min}$ per $\mathrm{kg}$ (Bonadonna et al. 1990). Thus, on average, under the influence of insulin, $6.7 \mu \mathrm{mol}$ glucose/min per $\mathrm{kg}(40 \%$ of $17 \mu \mathrm{mol} / \mathrm{min}$ per $\mathrm{kg}$ ) are oxidized at the cost of sparing $1.7 \mu \mathrm{mol} / \mathrm{min}$ per $\mathrm{kg}$ of circulating NEFA oxidation. This equivalence is close to the ratio of the energy equivalent of palmitate $(10.0 \mathrm{~kJ} / \mu \mathrm{mol})$ and glucose $(2.8 \mathrm{~kJ} / \mu \mathrm{mol})$, implying quantitative replacement of NEFA by glucose as fuel for oxidation. Thus, through substrate competition insulin suppression of plasma NEFA contributes significantly to whole-body insulin action at any age and regardless of obesity or gender. Furthermore, it could be calculated that the maximal contribution of NEFA suppression to insulin sensitivity is roughly equivalent to half the impact of obesity itself (as the BMI) on insulin sensitivity of glucose metabolism. Thus, a strictly metabolic factor is at play to modulate insulin sensitivity in both lean and obese subjects.

In the present study we have clearly demonstrated the relationships between insulin resistance, regulation of NEFA concentrations and obesity. Glucose regulation is strongly related to NEFA regulation in normal healthy subjects. The mechanisms whereby obesity can induce insulin resistance independent of NEFA concentrations have not been specifically identified.

On behalf of EGIR, we wish to thank Groupe Lipha in the person of Dr Christophe Pasik, for their generous support of the activities of the Group.

\section{REFERENCES}

Arner, P. (1995). Differences in lipolysis between human subcutaneous and omental adipose tissues. Annals of Medicine 27, 435-438.

Bonadonna, R. C., Groop, L. C., Simonson, D. C. \& DeFronzo, R. A. (1994). Free fatty acid and glucose metabolism in human aging: evidence for operation of the Randle cycle. American Journal of Physiology 266, E501-E509. 
Bonadonna, R. C., Groop, L. C., Zych, K., Shank, M. \& DeFronzo, R. A. (1990). Dose-dependent effect of insulin on plasma free-fatty acid turnover and oxidation in humans. American Journal of Physiology 259 , E739-E750.

Campbell, P. J., Carlson, M. G., Hill, J. O. \& Nurjhan, N. (1992). Regulation of free fatty acid metabolism by insulin in humans: role of lipolysis and reesterification. American Journal of Physiology 263, E1063-E1069.

Coon, P. J., Rogus, E. M., Drinkwater, D., Muller, D. C. \& Goldberg, A. P. (1992). Role of body fat distribution in the decline in insulin sensitivity and glucose tolerance with age. Journal of Clinical Endocrinology and Metabolism 75, 1125-1132.

Coppack, S. W., Jensen, M. D. \& Miles, J. M. (1994). The in vivo regulation of lipolysis in humans. Journal of Lipid Research 35, 177-193.

DeFronzo, R. A. (1979). Glucose tolerance and aging. Evidence for tissue insensitivity to insulin. Diabetes 28, 1095-1101.

DeFronzo, R. A., Tobin, J. A. \& Andres, R. (1979). Glucose clamp technique: a method for quantifying insulin secretion and resistance. American Joumal of Physiology 237, E214-E223.

Ferrannini, E., Smith, J. D., Cobelli, C., Toffolo, G., Pilo, A. \& DeFronzo, R. A. (1985). Effect of insulin on the distribution and disposition of glucose in man. Journal of Clinical Investigation 76, 357-364.

Ferrannini, E., Vichi, S., Beck-Nielsen, H., Laakso, M., Paolisso, G., Smith, U. \& European Group for the Study of Insulin Resistance (EGIR) (1996). Insulin action and age. Diabetes 45, 947-953.

Fink, R. I., Wallace, P. \& Olefsky, J. M. (1986). Effects of aging on glucose-mediated glucose disposal and glucose transport. Journal of Clinical Investigation 77, 2034-2041.

Frayn, K. N., Williams, C. M. \& Arner, P. (1996). Are increased plasma non-esterified fatty acid concentrations a risk marker for coronary heart disease and other chronic diseases? Clinical Science 90, 243-253.

Golay, A., Chen, Y. D. \& Reaven, G. M. (1986a). Effect of differences in glucose tolerance on insulin's ability to regulate carbohydrate and free fatty acid metabolism in obese individuals. Journal of Clinical Endocrinology and Metabolism, 62, 1081-1088.

Golay, A., Swislocki, A. L., Chen, Y. D., Jaspan, J. B. \& Reaven, G. M. (1986b). Effect of obesity on ambient plasma glucose, free fatty acid, insulin, growth hormone, and glucagon concentrations. Journal of Clinical Endocrinology and Metabolism 63, 481-484.

Groop, L. C. \& Ferrannini, E. (1993). Insulin action and substrate competition. Baillière's Clinical Endocrinology and Metabolism 7, 1007-1032.

Groop, L. C., Saloranta, C., Shank, M., Bonadonna, R. C., Ferrannini, E. \& DeFronzo, R. A. (1991). The role of free fatty acid metabolism in the pathogenesis of insulin resistance in obesity and noninsulin-dependent diabetes mellitus. Journal of Clinical Endocrinology and Metabolism 72, 96-107.

Hume, R. (1966). Prediction of lean body mass from height and weight. Journal of Clinical Pathology 19, 389391.

Kohrt, W. M., Kirwan, J. P., Staten, M. A., Bourey, R. E., King, D. S. \& Holloszy, J. O. (1993). Insulin resistance in aging is related to abdominal obesity. Diabetes 42, 273-281.

McGarry, J. D. (1992). What if Minkowski had been ageusic? An alternative angle on diabetes. Science 258, $766-770$

Polonsky, K. S., Given, B. D. \& Van Cauter, E. (1988). Twenty-four hour profiles and pulsatile patterns of insulin secretion in normal and obese subjects. Journal of Clinical Investigation 81, 442-448.

Randle, P. J., Garland, P. B., Hales, C. N. \& Newsholme, E. A. (1963). The glucose fatty-acid cycle. Its role in insulin sensitivity and the metabolic disturbances of diabetes mellitus. Lancet $\mathbf{i}, 785-789$.

Reaven, G. M., Hollenbeck, C., Jeng, C.-Y., Wu, M. S. \& Chen, Y.- D. I. (1988). Measurement of plasma glucose, free fatty acid, lactate and insulin for $24 \mathrm{~h}$ in patients with NIDDM. Diabetes 37, 1020-1024.

Robert, J. J., Cummins, J. C., Wolfe, R. R., Durkot, M., Matthews, D. E., Zhao, X. H., Bier, D. M. \& Young, V. R. (1982). Quantitative aspects of glucose production and metabolism in healthy elderly subjects. Diabetes 31, 203-211.

World Health Organization Expert Committee on Diabetes Mellitus (1980). Diabetes Mellitus. WHO Technical Report Series no. 646. Geneva: WHO.

\section{APPENDIX}

\section{Members of the European Group for the Study of Insulin Resistance (EGIR)}

H. Beck-Nielsen
P. M. Bell
E. Bonora
B. Capaldo
P. Cavallo-Perin
University of Odense, Denmark

University of Belfast, Northern Ireland, UK

University of Verona, Italy

Frederico II University, Naples, Italy

University of Turin, Italy 
S. W. Coppack

S. Del Prato

E. Ferrannini

D. Fliser

A. Golay

L. C. Groop

S. Jacob

M. Laasko

N. Lalic

G. Mingrone

A. Mitrakou

G. Paolisso

K. Rett

U. Smith

M. Weck

H. Yki-Jarvinen
University College of London, London, UK

University of Padova, Italy

CNR Institute of Clinical Physiology, Pisa, Italy

Ruperto-Carola University, Heidelberg, Germany

Geneva University Hospital, Geneva, Switzerland

Lund University, Lund, Sweden

Stadtklinik, Baden-Baden, Germany

University of Kuopio, Finland

University of Belgrade, Belgrade, Serbia

Catholic University, Rome, Italy

University of Athens, Athens, Greece

University of Naples II, Napoli, Italy

University of München, München, Germany

University of Goteborg, Goteborg, Sweden

Kreisha, Germany

University of Helsinki, Helsinki, Finland 